УДК 665.65

\title{
Improving the Reliability of the Plant Production of Sulfur
}

\author{
Evgeny A. Chumakov ${ }^{\mathrm{a}}$, Roman A. Vaganov, \\ Fedor A. Buryukin ${ }^{\mathrm{b}}$ and Dmitry A. Mel'chakov ${ }^{\mathrm{a}}$ \\ ${ }^{a}$ J.S.C. "Achinsk Oil Refinery of E. O. C.» \\ Industrial Zone Refinery, Bolsheuluysky District, \\ Krasnoyarsk region, 662110, Russia \\ ${ }^{b}$ Siberian Federal University \\ 79 Svobodny, Krasnoyarsk, 660041, Russia
}

Received 09.03.2017, received in revised form 26.05.2017, accepted 18.07.2017

The experience of modernization of the production of sulfur by the Claus at JSC «Achinsk Oil Refinery of E. O. C.». The measures for replacement of the contact device sulfur trap, the enrichment of air with oxygen in the thermal stage of the process. Activities under taken on modernization of production of sulfur allowed to increase output (granulated sulfur), to reduce the load on the main and auxiliary equipment installation, ensure smooth operation ofthe installation.

Keywords: the Claus process, hydrogen sulfide gas, granulated sulfur, membrane plants, modernization, oxygen enrichment, the contact device.

DOI: $10.17516 / 1998-2836-0039$.

(C) Siberian Federal University. All rights reserved

* Corresponding author E-mail address: vaganov.roman@mail.ru 


\title{
Повышение надежности работы установки производства серы
}

\author{
Е.А. Чумаков ${ }^{a}$, Р.А. Ваганов ${ }^{\sigma}$, \\ Ф.А. Бурюкин \\ ${ }^{a} \mathrm{AO}$ «АНПЗ ВНК» \\ Россия, 662110, Красноярский край, \\ Большеулуйский район, промзона НПЗ \\ ${ }^{6}$ Сибирский федеральный университет \\ Россия, 660041, Красноярск, пр. Свободный, 79
}

Представлен опыт модернизации установки производства серы по методу Клауса в АO «АНПЗ ВНК». Предложены мероприятия по замене контактного устройства сероуловителя, обогащению воздуха кислородом на термической стадии прочесса. Проведенные мероприятия по модернизации установки производства серы позволили увеличить выпуск продукции (гранулированной серы), снизить нагрузку на основное и вспомогательное оборудование установки, обеспечить бесперебойную работу установки.

Ключевые слова: прочесс Клауса, сероводородсодержащий газ, гранулированная сера, мембранные установки, модернизация, обогащение кислородом.

\section{Введение}

С середины прошлого века интенсивно вовлекается в переработку нефть с повышенным содержанием серы. Типовые схемы переработки нефти включают в себя процессы очистки от сернистых соединений в присутствии катализаторов под давлением водорода (гидроочистка, гидрокрекинг). При очистке углеводородного сырья образуется сероводородсодержащий газ, который направляется на получение серы или серной кислоты. В настоящее время более 90 \% выпускаемой в России серы производится таким способом. Отделение $\mathrm{H}_{2} \mathrm{~S}$ происходит на установках аминовой очистки и отпарки кислых стоков. В последнем случае газ помимо $\mathrm{H}_{2} \mathrm{~S}$ содержит аммиак [1].

Первые промышленные установки получения серы позволяли утилизировать 80-90 \% образующегося сероводородсодержащего газа. Оставшийся сероводородсодержащий газ сжигался в печах дожига и в виде диоксида серы выбрасывался в атмосферу.

С каждым годом экологические требования ужесточаются, а также усиливается контроль за мониторингом выбросов от промышленных предприятий.

Переработка сероводородного газа в АО «АНПЗ ВНК» производится по четырехступенчатому окислительному методу Клауса с применением одной термической и трех каталитических ступеней. Мощность установки по сырью составляет 7 тыс. т в год. Производительность установки может варьироваться в интервале 60-120\% от номинальной [2].

Процесс утилизации сероводородсодержащего газа по методу Клауса считается наиболее универсальным и экономически эффективным [3]. Этот метод позволяет значительно снизить 
выброс загрязняющих веществ в окружающую среду, а также получить дополнительное количество товарной продукции.

На рис. 1 представлена принципиальная схема установки утилизации сероводородсодержащего газа и производства гранулированной серы, применяемая на Ачинском НПЗ.

Термическая стадия процесса заключается в высокотемпературном сжигании сероводорода в топке котла-утилизатора при подаче воздуха по реакции [4]

$$
2 \mathrm{H}_{2} \mathrm{~S}+\mathrm{O}_{2} \rightarrow 2 \mathrm{H}_{2} \mathrm{O}+\mathrm{S}_{2}+\text { Q }
$$

Стехиометрическое соотношение количества воздуха и сероводорода (отношение объема воздуха к объему сероводородного газа) в зависимости от состава сероводородного газа находится в пределах от 2:1 до 3:1.

Реакции окисления протекает при температуре $1250-1350{ }^{\circ} \mathrm{C}$ в зависимости от концентрации $\mathrm{H}_{2} \mathrm{~S}$ в сероводородном газе и наличия в нем углеводородов и аммиака. При указанной температуре часть сероводородного газа в топке котла-утилизатора превращается в $\mathrm{SO}_{2}$.

Также в процессе возможно протекание побочных реакций с образованием $\mathrm{COS}, \mathrm{CS}_{2}, \mathrm{CO}$, $\mathrm{H}_{2}$ и сгорание углеводородов и аммиака.

При охлаждении газов после термической ступени происходят следующие процессы:

- ассоциация молекул $\mathrm{S}_{2}$ в $\mathrm{S}_{6}$ и $\mathrm{S}_{8}$;

- ассоциация молекул серы $\mathrm{S}_{6}$ в $\mathrm{S}_{8}$;

- конденсация серы.

При выборе оптимального режима работы установки производства серы по методу Клауса используется значение равновесной конверсии сероводорода [2]. Равновесная конверсия серо-

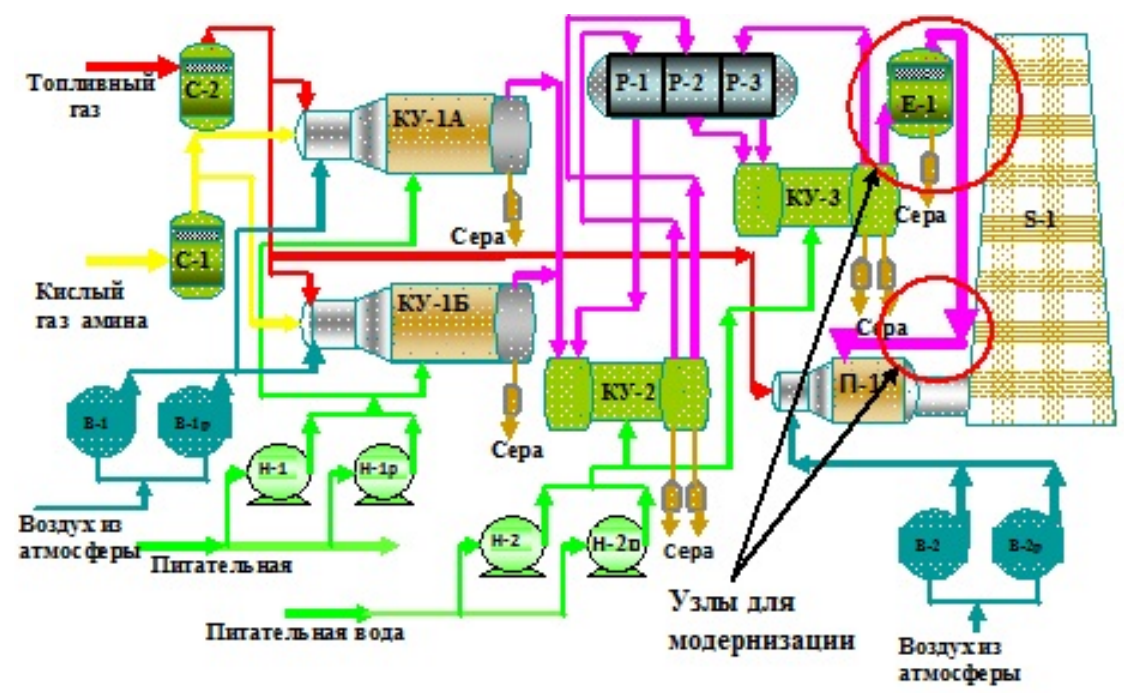

Рис. 1. Принципиальная схема установки утилизации сероводородсодержащего газа: Н-1, Н-1p, Н-2, Н-2p - насос; В-1, В-1p, В-2, В-2p - воздуходувка; C-1, С-2 - сепаратор; КУ-1А, КУ-1Б, КУ-2, КУ-3 - котелутилизатор; Р-1, Р-2, Р-3 - реактор; Е-1 - емкость-сероуловитель; П-1 - печь дожига; S-1- труба печная

Fig. 1. Schematic diagram of the unit for the utilization of hydrogen sulphide-containing gas: H-1, H-1p, H-2, H-2p - pump; B-1, B-1p, B-2, B-2p - blower; C-1, C-2 - separator; KУ-1A, КУ-1Б, KУ-2, KУ-3 - waste heat boiler; P-1, P-2, P-3 - reactor; E-1 - grease trap; П-1 - afterburner; S-1- chimney 
водорода в первую очередь зависит от температуры в камере сгорания термической ступени. Достичь равновесную конверсию в реальных условиях не представляется возможным, так как на равновесие системы влияют следующие факторы: давление, соотношение $\mathrm{H} 2 \mathrm{~S}: \mathrm{O} 2$, содержание углеводородных газов, $\mathrm{CO} 2, \mathrm{H}_{2} \mathrm{O}$ и др. [5].

Равновесная конверсия сероводорода на термической стадии составляет не более 70 \%. С учетом каталитических стадий процесса конверсия сероводорода увеличивается до 95 - $95 \%$ (рис. 2) [6].

На каталитических ступенях процесса при температуре от 240 до $320^{\circ} \mathrm{C}$ (слой катализатоpa CRS 31 и слой катализатора CR 3S производства компании «Axens» в конверторе I ступени P-1), от 215 до $260^{\circ} \mathrm{C}$ (слой катализатора CRS 31 в конверторе II ступени P-2) и от 205 до $225{ }^{\circ} \mathrm{C}$ (слой катализатора CRS 31 в конверторе III ступени Р-3) на катализаторе происходит конверсия $\mathrm{H}_{2} \mathrm{~S}$ и $\mathrm{SO}_{2}$ с образованием серы. При наличии алюмооксидного катализатора на ступени I конверсии происходит гидролиз $\mathrm{COS}$ и $\mathrm{CS}_{2}$. Состав катализаторов приведен в табл. 1.

Применение трех каталитических ступеней способствуют увеличению выхода серы вследствие более низкой температуры реакций в третьей ступени по сравнению с первой и второй. Отвод серы из газовой фазы сдвигает равновесие в сторону увеличения выхода и снижает температуру точки росы серы в технологическом газе. Выход серы составляет 98 \% масс.

Непрореагировавший сероводород сжигается в печи дожига П-1 со сбросом отходящих газов в атмосферу через существующую дымовую трубу S-1 высотой 125 м.

\section{Цель работы}

В ходе эксплуатации установки утилизации сероводородсодержащего газа и производства серы выявлены следующие недостатки:

- унос капельной серы с технологическим газом;

- конденсация серы в трубопроводе до печи дожига (рис. 1).

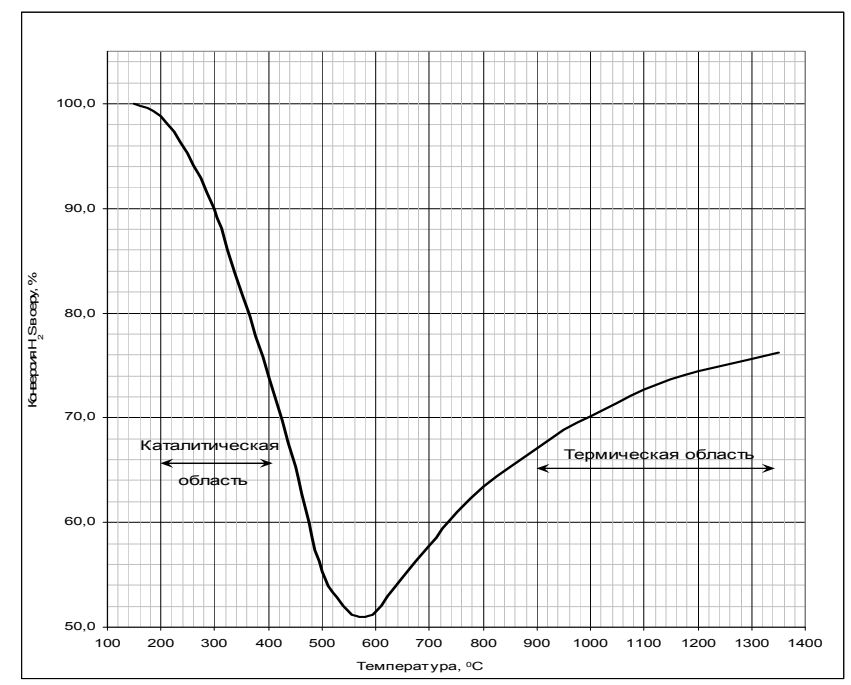

Рис. 2. Равновесная конверсия H2S в элементарную серу

Fig. 2. Equilibrium conversion of $\mathrm{H} 2 \mathrm{~S}$ to elemental sulfur

$$
-440-
$$


Таблица 1. Характеристики катализаторов процесса Клауса

Table 1. Characteristics of the catalysts of the Claus process

\begin{tabular}{|c|c|c|c|}
\hline № п.п. & $\begin{array}{c}\text { Показатель/марка } \\
\text { катализатора }\end{array}$ & $\begin{array}{c}\text { Катализатор Клауса } \\
\text { марки CR 3S }\end{array}$ & $\begin{array}{c}\text { Катализатор Клауса } \\
\text { марки CRS 31 }\end{array}$ \\
\hline 1 & Состав, \% вес. & $\begin{array}{c}\mathrm{Al}_{2} \mathrm{O}_{3}-\text { не менее } 93,8 \\
\mathrm{Na}_{2} \mathrm{O}-\text { не более } 0,0024\end{array}$ & $\mathrm{TiO}_{2}-$ не менее 85 \\
\hline 2 & Агрегатное состояние & твердое & твердое (экструдаты) \\
\hline 3 & Диаметр гранул, мм & $3 \div 6$ & 0,92 \\
\hline 4 & $\begin{array}{c}\text { Средняя насыпная } \\
\text { плотность, } / \mathbf{M}^{3}\end{array}$ & $0,68 \div 0,74$ & 3 \\
\hline
\end{tabular}

Возможными причинами вышеуказанных процессов является:

- неэффективная работа сероуловителя Е-1, связанная с неудовлетворительной работой сетчатого каплеуловителя, а также недостаточным внутренним объемом сероуловителя;

- увеличенная проектная нагрузка по расходу сероводородного газа на каждый котелутилизатор с 315 до 395 м³/ч, что связано с высокой скоростью технологического газа в сероуловителе;

- большая протяженность трубопровода от сероуловителя до печи дожига (104 м) и недостаточная его теплоизоляция (40 мм).

\section{Технические решения}

Проблема уноса капельной серы устраняется установкой более эффективного лопаточного каплеуловителя в действующей сероуловитель и снижением линейной скорости технологического газа в сероуловителе.

Объем действующего сероуловителя E-1 составляет 0,57 м², скорость потока газа в нем 2,97 м/с. В качестве контактного устройства используется сетка Панченко. Опыт эксплуатации установки показал, что сетка Панченко не способна предотвратить унос капельной серы с сероуловителя в трубопровод до печи дожига при используемых технологических режимах.

Нами предлагается заменить сетчатый каплеуловитель на лопаточный каплеуловитель (рис. $3 a$ ), что снизит унос капельной серы с технологическим газом. Данная модернизация позволяет увеличить отбор жидкой серы и снизить выбросы загрязняющих веществ в окружающую среду.

Лопаточный каплеуловитель (рис. $3 a$ ) способствует отделению капельной жидкости при горизонтальном прохождении газового потока. Газовый поток, содержащий капельную жидкость, направляется через камеры каплеуловителя, конструкция которых обеспечивает максимальное воздействие на газовый поток.

Благодаря конструкции контактного устройства лопаточного каплеуловителя (рис. 3б) на капли жидкости воздействуют инерционные силы. Капли ударяются о поверхность профилей, где образуют жидкую пленку, которая затем сливается под действием силы тяжести. Отделительные камеры специальной формы обеспечивают надлежащий слив жидкости, одновременно улавливая очень мелкие капли.

$$
-441-
$$




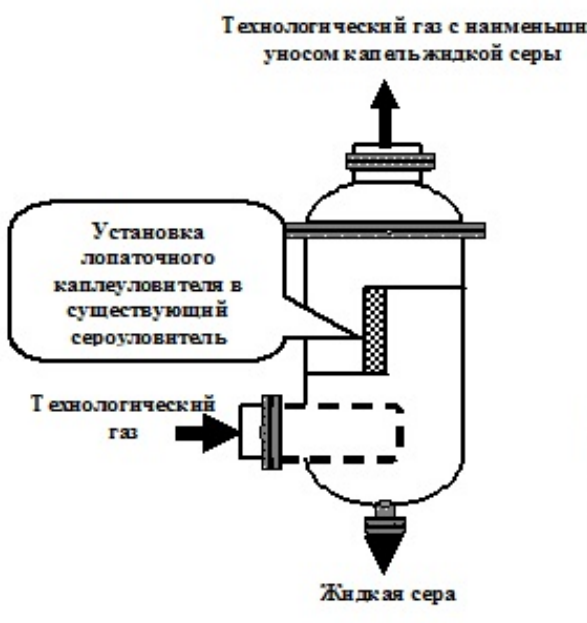

a

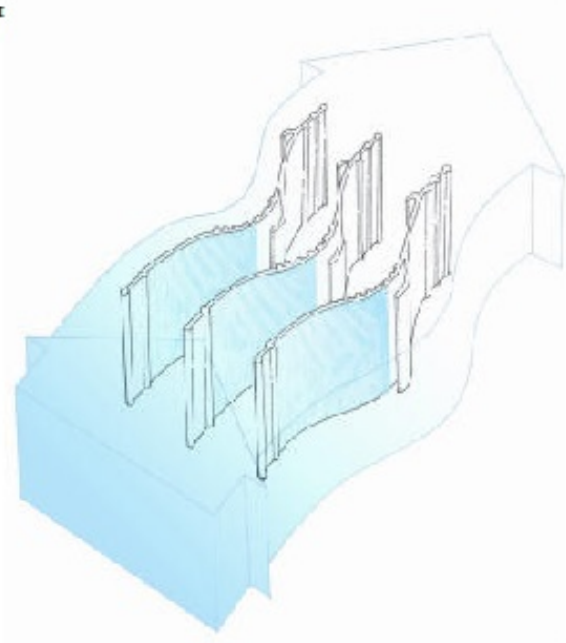

б

Рис. 3. Принципиальный вид реконструкции действующего сероуловителя (а) и внутреннее контактное устройство лопаточного каплеуловителя (б)

Fig. 3. Principal view of the reconstruction of the operating grease trap (a) and the internal contact device of the blade drop eliminator (b)

Внедрение нового лопаточного каплеуловителя в АО «АНПЗ ВНК» позволило увеличить выпуск продукции (гранулированной серы) и снизить нагрузку на воздуходувки и печи дожига.

В продолжение работ по модернизации установки производства серы определили, что снижение скорости газа в сероуловителе можно достичь двумя путями:

- увеличить объем сероуловителя при сохранении расхода технологического газа;

- снизить расход технологического газа, поступающего в сероуловитель, за счет обогащения воздуха (для термической стадии процесса Клауса) кислородом и снижения стехиометрического соотношения воздух: сероводородсодержащий газ.

Наиболее эффективным и комплексным, на наш взгляд, является метод обогащения воздуха кислородом. Незначительное увеличение процентного содержания кислорода в воздухе позволяет увеличить мощности установок, повысить коэффициент полноты сгорания сырья в топочной камере котла-утилизатора. В процессе получения сероводородсодержащего газа также образуется аммиачный газ. В результате этого в технологическом газе появляются аммониевые соли, которые закупоривают трубки теплообменного оборудования, трубопроводы, что служит источником для возникновения аварийных ситуаций. Использование воздуха, обогащенного кислородом, способствует разложению аммиака и сводит к минимуму образование аммониевых солей. Кроме того, кислород активизирует горение тощих нефтяных газов с высоким содержанием сероводорода [7].

В АО «Ачинский НПЗ ВНК» среднее содержание сероводорода в газе составляет 97,0 \%

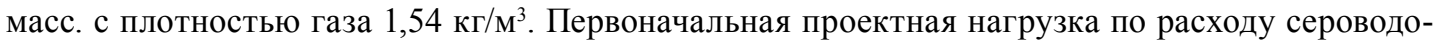
родного газа на установку равнялась 630 м³/ч. Вследствие того, что на НПЗ для соответствия

$$
-442-
$$


моторных топлив экологическим требованиям постоянно увеличивается степень очистки от серы, а также, в перспективе, может быть осуществлен переход на переработку высокосернистой нефти, нагрузка на установку производства серы возрастет. Поэтому после согласования с проектной организацией нагрузка по расходу сероводородного газа была увеличена до $790 \mathrm{M}^{3} /$ ч.

Для сжигания сероводородсодержащего газа предусмотрена подача воздуходувками технологического воздуха для поддержания стехиометрического соотношения «газ-воздух». Производительность воздуходувок составляет $1980 \mathrm{~m}^{3} /$ п при содержании кислорода $21 \%$ об. При максимальной загрузке установки производства серы отмечается недостаток технологического воздуха для сжигания сероводородного газа. При увеличении концентрации $\mathrm{O}_{2}$ в технологическом воздухе до $41 \%$ об. количество воздуха, требуемого для сжигания 790 м $3 /$ ч сероводородсодержащего газа ( $\mathrm{H}_{2} \mathrm{~S}-97,0 \%$ об.), снижается до 1378 м³/ч.

Таким образом, увеличение концентрации $\mathrm{O}_{2}$ в технологическом воздухе позволяет увеличить производительность установки по сероводородному газу в среднем на 28 \% об. [8].

Обогащение технологического воздуха кислородом снижает количество азота, подаваемого в технологический процесс и являющегося балластом. Следовательно, при одинаковом расходе $\mathrm{H}_{2} \mathrm{~S}$-содержащего газа линейная скорость газа в сероуловителе при обогащении воздуха кислородом меньше, чем при использовании технологического воздуха, содержащего 21 \% об. кислорода.

Обогащение кислородом происходит за счет смешивания обогащенного кислородом воздуха с воздухом, подаваемым в камеру сгорания, для доведения содержания кислорода до требуемого процентного содержания от общего объема подаваемого воздуха.

На рис. 4 показаны различные способы получения кислорода для смешения его с технологическим воздухом (по данным АО «Грасис»).

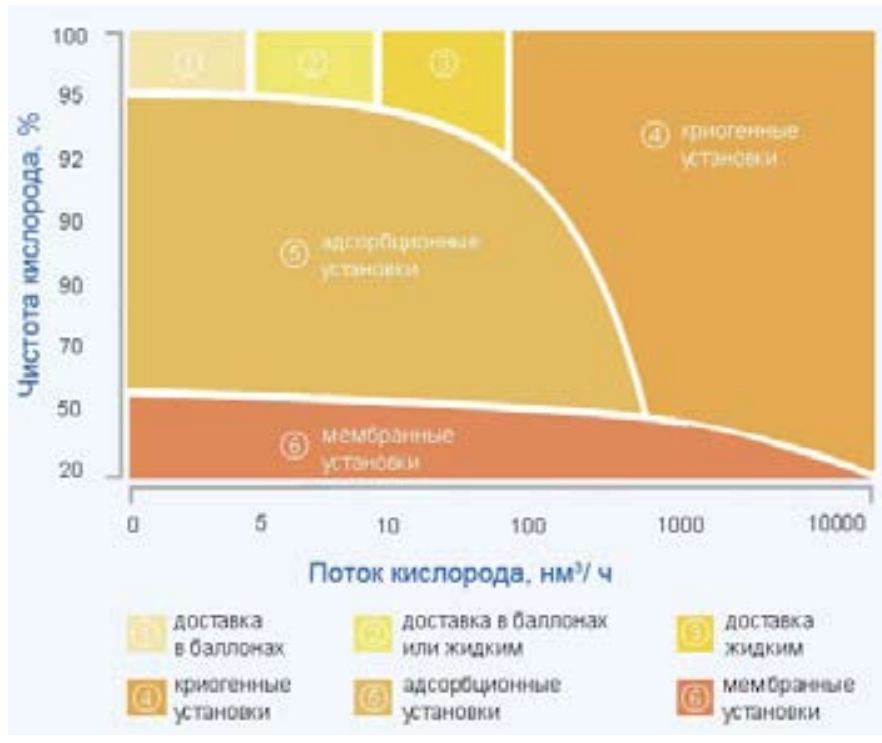

Рис. 4. Технологии для производства кислорода

Fig. 4. Technologies for the production of oxygen

$$
-443-
$$


Первые три способа позволяют использовать кислород высокой чистоты (содержание $\mathrm{O}_{2}>95 \%$ об.), однако имеют низкий поток кислорода, что не удовлетворяет требованиям по эксплуатации промышленной установки производства серы.

Адсорбционные и криогенные установки позволяют получать достаточное количество кислорода (содержание $\mathrm{O}_{2}$ от 50 до 90 \% об.), но требуют больших энергетических затрат (криогенные установки) и высокоактивных дорогостоящих адсорбентов (адсорбционные установки).

Относительной простотой и экономической целесообразностью, на наш взгляд, обладают мембранные установки. Они позволяют производить большой поток кислорода (содержание $\mathrm{O}_{2}$ от 21 до 50 \% об.), что в полной мере удовлетворяет технологии процесса Клауса.

Принцип работы мембранных систем основан на разнице в скорости проникновения компонентов газа через вещество мембраны. Половолоконная мембрана состоит из пористого полимерного волокна с нанесенным на его внешнюю поверхность газоразделительным слоем. Конструктивно половолоконная мембрана компонуется в виде цилиндрического картриджа, который представляет собой катушку с намотанным на нее особым образом полимерным волокном; принципиальный вид данного картриджа изображен на рис. 5 (по данным АО «Грасис»).

Газовый поток под давлением подается в пучок мембранных волокон. Разделение газовой смеси происходит за счет разницы парциальных давлений на внешней и внутренней поверхностях половолоконной мембраны. Газы, «быстро» проникающие через полимерную мембрану (например: $\mathrm{H}_{2}, \mathrm{CO}_{2}, \mathrm{O}_{2}$, пары воды), поступают внутрь волокон и выходят из мембранного картриджа через один из выходных патрубков. Газы, «медленно» проникающие через мембрану (например, $\mathrm{CO}, \mathrm{N}_{2}, \mathrm{CH}_{4}$, высшие углеводороды), выходят из мембранного модуля через второй выходной патрубок [7, 8].

В качестве системы управления мембранной кислородной установкой используются высокоинтеллектуальные системы управления, которые обеспечивают полный контроль над работой установки $[7,8]$.

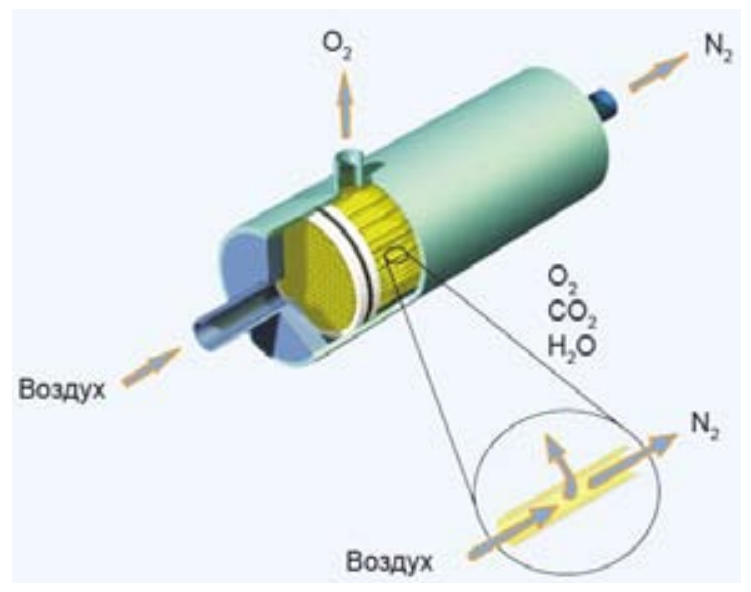

Рис. 5. Принципиальный вид мембранного цилиндрического картриджа

Fig. 5. Principal view of a membrane cylindrical cartridge 
Как отмечалось ранее, эксплуатация установки утилизации сероводородного газа и производства гранулированной серы показала, что периодически происходит конденсация и отложение серы на внутренней поверхности трубопровода от сероуловителя Е-1 до печи дожига П-1. Ввиду того, что по проекту толщина теплоизоляционного слоя составляет 40 мм, температура стенки трубопровода перед печью дожига уменьшается и происходит отложение серы на стенках трубопровода.

Отложения серы накапливаются и ухудшают пропускную способность трубопровода, что приводит к снижению производительности установки и увеличению давления в газовом тракте. Забивание трубопровода может также привести к аварийной остановке установки.

Для минимизации конденсации и отложения серы на внутренней поверхности трубопровода от сероуловителя до печи дожига предлагается смонтировать электрообогрев для поддержания температуры стенки трубопроводав пределах 130-135 ${ }^{\circ} \mathrm{C}$.

В качестве источника для электрообогрева стенок трубопровода до печи дожига возможен саморегулирующийся греющий кабель. После проведения тепловых и материальных расчетов определена его длина - 430 м.

\section{Выводы}

Таким образом, внедрение нового лопаточного каплеуловителя в АО «АНПЗ ВНК» и использование метода обогащения технологического воздуха кислородом позволило увеличить выпуск продукции (гранулированной серы) и снизить нагрузку на воздуходувки и печи дожига.

Проблема конденсации и отложения серы на внутренней поверхности трубопровода решена монтированием электрообогрева для поддержания температуры стенки трубопровода. Это дало возможность минимизировать риски остановки установки и сброса сероводородного газа на факел.

\section{Список литературы}

1. Подшивалин А.В. Современная технология производства элементарной серы. Heфтеггазовое дело. 2006. № 1. С. 231-234. [Podshivalin A.V. Modern technology of elementary sulfur production. Oil and gas business. 2006. № 1. P. 231-234. (In Russ.)]

2. Касюк Ю.М., Дружинин О.А., Анисимов С.Н., Пахомов С.С., Мельчаков Д.А., Хандархаев С.В., Твердохлебов В.П., Бурюкин Ф.А., Голованов И.В. Проектные и технические решения по строительству установки утилизации сероводородсодержащего газа на ОАО «АНПЗ ВНК». Технология нефти и газа. 2009. № 6. С. 3-7. [Kasyuk Yu.M., Druzhinin O.A., Anisimov S.N., Pakhomov S.S., Melchakov D.A., Khandarkhaev S.V., Tverdokhlebov V.P., Buriukin F.A., Golovanov I.V. Design and technical solutions for the construction of a hydrogen sulfide-containing gas utilization unit at JSC "ANPZ VNK". Technology of oil and gas. 2009. No. 6. P. 3-7.]

3. Касюк Ю.М., Дружинин О.А., Анисимов С.Н., Пахомов С.С., Мельчаков Д.А., Хандархаев С.В., Твердохлебов В.П., Бурюкин Ф.А., Голованов И.В. Проектные и технические решения по строительству установки утилизации сероводородсодержащего газа на ОАО «АНПЗ ВНК». Мир нефтепродуктов. Вестник нефтяных компаний. 2009. № 4. С. 12-15. [Kasyuk Yu.M., Druzhinin O.A., Anisimov S.N., Pakhomov S.S., Melchakov D.A., Khandarkhaev S.V.,

$$
-445-
$$


Tverdokhlebov V.P., Buriukin F.A., Golovanov I.V. Design and technical solutions for the construction of a hydrogen sulfide-containing gas utilization unit at JSC «ANPZ VNK». World of oil products. Bulletin of oil companies. 2009. No. 4. P. 12-15. (In Russ.)]

4. Соркин Я.Г. Особенности переработки сернистых нефтей и охрана окружающей среды. М., Химия, 1975. [Sorkin Ya.G. Features of processing of sulphurous oils and environmental protection. M., Chemistry, 1975].

5. Жоров Ю.М. Термодинамика химических процессов. Нефтехимический синтез, переработка нефти, угля и природного газа. М.: Химия, 1985. 464 с. [Zhorov Yu.M. Thermodynamics of chemical processes. Petrochemical synthesis, processing of oil, coal and natural gas. M.: Chemistry, 1985. 464 p. (In Russ.)]

6. Аяпбергенов Е.О. Особенности технологии получения элементарной серы на установках Клауса из сероводорода кислых газов. Современные научные исследования и инновации. 2012. № 10 [Электронный ресурс]. URL: http://web.snauka.ru/issues/2012/10/17654 [Ayapbergenov E.O. Features of the technology for obtaining elemental sulfur in the Claus plants from hydrogen sulphide hydrogen gases. Modern scientific research and innovations. 2012. № 10 [Electronic resource] (In Russ.). URL: http://web.snauka.com/issues/2012/10/17654]

7. Ahamparam S., Harrison S., Linde. Oxygen enrichment of desulphurization process. Oil and gas technologies. 2013. № 7. P. 90-92.

8. Chandrasekaran S., Rajamani N.K., Joshi M.K., Goyal C.D. Technology of enrichment with oxygen. Oil and gas technologies. 2011. № 7. P. 81-82. 